\title{
PROBLEMS OF FAMILIES WITH A CHILD WITH AN INCURABLE DISEASE IN THE CONTEXT OF SPECIAL EDUCATION
}

\author{
Kristína Nagyová ${ }^{1}$, Terézia Harčaríková ${ }^{2}$
}

\begin{abstract}
The issue of incurable diseases, today, represents a relatively current and urgent topic because, despite the development of medicine and comprehensive care for individuals with an incurable disease, there is a continual increase in the number of such diseases associated with secondary problems that have a crucial bearing on the quality of life for the individuals and their family in both a broader and narrower context. An important role in the comprehensive care of individuals with an incurable disease is special education, because in addition to education it deals with the stigma attached to the care and education of families with a child with an incurable disease. The paper presents the partial results of research focused on the problems of individuals with oncological disease in the context of special education. Research data were obtained by a variety of methods, where the most crucial were the semi-structured interview method and the method of narration. These methods were applied on individuals with oncological disease who had been diagnosed with cancer during the time of schooling. The obtained data were processed by qualitative analysis. The results indicate that this issue requires greater consideration.
\end{abstract}

JEL Classification Numbers: I2, I20 DOI: http://dx.doi.org/10.12955/cbup.v4.831

UDC Classification: 376

Keywords: oncological disease, family, incurable disease, individuals with an incurable disease.

\section{Multidimensional Context of Illness}

Disease can be viewed as a multifactorial phenomenon from several perspectives, particularly, the medical, social, educational, and special educational view as well as from a psychological understanding. Medical illness may be characterized as any disturbance of structure or function of the body that is often associated with apparent structural changes, e.g., lesions in various organs (Crowley, 2014).

As Harčaríková (2011) wrote, the social viewpoint mainly relates to perceptions and attitudes towards the disease in terms of the individual with the disease. That is, the impact of disease is a consequence of changes in the social life of an individual, specifically, the change in the identity of the individual with the disease and changing social roles based on the permanent consequences of the disease (Vágnerová, 1999; Kapr, 1986).

Special educational viewpoints concern, in particular, restrictions on education and the need for modification and reduction of the curriculum. In addition, it concerns the essential role and function of special teachers to work with the individuals, as well as with the individual's family.

In terms of psychology, the reaction of the individual with an incurable illness and their family, and their acceptance of this disease are especially significant.

An incurable illness represents one that ends in death of the individual. These are diseases that progress and draw on all treatments because there is no current understanding of how to cure or prevent their progress (Jasenková \& Mikesková, 2005). Building on the above information, it is clear that the notion of "an individual with the incurable disease" defines an individual with a "lethal" disease, whereby the term lethal is understood to mean fatal or life-threatening (Nagyová, 2015a).

We consider it crucial to connect the care for individuals with incurable disease with the scientific field of special education. The area of special-care for individuals with incurable diseases in Slovakia is relatively undeveloped. Possibly, one reason for this is that the education of terminally-ill children falls within the more recent discipline of special education, i.e., pedagogy of individuals with physical

\footnotetext{
${ }^{1}$ Kristína Nagyová, Faculty of Education, Department of Special Education, Comenius University in Bratislava, Slovakia, nagyova.kristina25@gmail.com

${ }^{2}$ Terézia Harčaríková, Faculty of Education, Department of Special Education, Comenius University in Bratislava, Slovakia, harcarikova@fedu.uniba.sk
} 
disabilities, illnesses, and debilitated. Another is the high taboo in relation to the incidence of lethal diseases and the promotion of particular medical, psychological, and curative educational care. Nonetheless, it should be noted that the educational care for these individuals is an important aspect of a comprehensive approach and care for individuals with incurable diseases (Nagyová, 2016).

Medical Care for Individuals with Incurable Illness

It is vital to highlight that, in Slovakia, palliative care exists with the corresponding hospice care and treatment that is most often associated with oncological disease. This relationship between palliative and hospice care needs separation, because palliative with hospice care is given to all children and adolescents who suffer from an incurable disease (Jasenková \& Mikesková, 2005).

Currently, the prevalence of incurable diseases is quite high. Jasenková and Mikesková (2005) indicated that 10 out of 10,000 children aged 0 to 19 years will have an incurable illness. Annually, about half of these children, i.e., 745 children, require palliative care (Nagyová, 2015b).

Showing a basic categorization of constituent incurable diseases is difficult, since these diseases are numbered and classified from different perspectives, e.g., etiology, time of onset, and prognosis. However, as reported in Nagyová, (2015a), incurable childhood diseases (life-limiting or lifethreatening) have been classified by Jasenková (2005) as follows:

- Diseases with the possibility of curative treatment, however treatment may fail, e.g., cancers and organ failure;

- Diseases with the possibility of prolonging life with intensive treatment, e.g., cystic fibrosis and AIDS;

- Diseases with possibility of palliative treatment since diagnosis, e.g., severe metabolic and neurodegenerative diseases; and

- Diseases with severe non-progressive nature, e.g., severe neurological diseases, developmental anomalies, and accident conditions with traumatic brain injury.

\section{Social Care for Individuals with Incurable Illness}

Individuals with oncological disease, especially children, are severely addicted and dependent on their social surroundings.

For children and students, the primary social consequence is the lack of being able to fully participate as pupils in a school environment. A fully fledged role of a pupil in favorable conditions offsets the role of pupils in schools of a healthcare facility accommodating sick individuals, with cases of conditions being unsuitable for education and individuals evading the role of pupil (Harčaríková \& Nagyová, 2015).

Another social consequence is the loss or limitation of social contacts (peers, classmates, and friends) and loss of social identity. Long-term hospitalization with restricted expression is significantly reflected in the self-views of individuals who develop feelings of uselessness and inferiority (Svatová, 2010).

Based on the research, we have found that the relationships of classmates with individuals returning to school after recovery from disease remained unchanged. An important finding was the avoidance in the elementary school of the those in an acute stage of disease by some classmates and students for fear they would also will fall sick. Nevertheless, in elementary school, each respondent maintained contact with students and classroom teachers with friendly communication, and communicated with teachers about curriculum, notes, and tests. We emphasize that it was important for individuals with ill health to preserve contact with classmates and peers for a sense of belonging. It was also crucial that they conversed about the disease without pressure, as respondents reported in our research, that they had not talked with friends about the disease, although their friends were of great support and encouraging throughout their treatment.

Special Educational Care for Individuals with Incurable Illness

Progress in modern medicine has increased survival chances and opportunities to improve the health of children and students who suffer from long-term, chronic, or life-threatening illness. More 
importantly, these children and students can return to school, school groups, and their normal lives (Harčaríková \& Nagyová, 2015).

The basics of educating children with a disease involve various parts of the educational process, but in particular, the surrounds, since in most cases education is carried out in hospital or at home, and the conduct of the educator, i.e., the special-education teacher (or general teacher with the help of an assistant). A special-education teacher is an important element of a multidisciplinary team consisting of doctors, nurses, therapists, social workers, and other caregivers. As a team, they have the same goals, which are to help the child feel better and be healthy, without disrupting normal development and education (Carstens, 2004).

Nagyová (2015a) identified the important element to be the specificity of the subject receiving the education, i.e., the individual with lethal disease. In most cases, education proceeds on an individual basis at an individual pace, according to the health condition of the individual. Another trait is the form of education, which, in the case of an individual with disease in the hospital, involves fully "adapted treatment regimen of medical devices" (Harčaríková, 2011, p. 155).

The acute problem relating to the education of individuals with a disease is the education of secondary school students. This is due to all higher secondary educational activities being solely their own and their parent's responsibility, since in practice, the special-education teachers focus on working with children and students of pre-primary, primary, and lower secondary education.

Organizing care to help an adolescent is undoubtedly one of the most challenging tasks in palliative care. With adolescents, the physical and emotional changes during the terminal stage of the disease are more complicated. The adolescent period is associated with a number of crucial changes, among which includes seeking independence and finding their identity. Adolescents use many possible ways to discover new insights into themselves and their surroundings, and care efforts often become ambivalent. On the one hand, adolescents need to find their "own way" during which they make mistakes while endeavoring something new. On the other hand, at the same time they depend on the presence and support of their parents (Bild \& Gómez, 2014). In addition, individuals with the disease who are hospitalized long-term or isolated from the outside world at home, have no full-fledged fulfillment and implementation of these crucial changes.

In addition to fulfilling the various developmental changes, educational care is an essential part of comprehensive care for individuals with a disease, whether for an individual with a favorable prognosis or one requiring provision of palliative care. Under educational care, an individual receives education at the time of hospitalization, at the hospital in the hospital's designated area, or at home (Nagyová, 2016).

Based on a study of the available literature and research, dealing with issues of educating pupils with incurable disease, consideration is needed of the impact of disease and treatment on educational outcomes and intellectual abilities, and the necessary part of education that is schooling, is neglected (Nagyová, 2016).

\section{Psychology Care for Individuals with Incurable Illness}

Any chronic or acute disease represents a huge burden on the child's psyche and organism. The disease restricts general encounters for the child and brings new, non-standard experiences, causing the individual to react to their illness and change their psyche.

Long-term hospitalization of children and pupils with an incurable disease leads to change in personality in response to the situation. Hospitalization causes significant changes in one's lifestyle. The individual is taken from their natural social environment, with disease limiting their contact with their everyday social network and peers, who represent the individual's key school-aged social sector (Harčaríková \& Nagyová, 2015).

The effect of severe disease manifests in all areas of human personality. It affects the biological, social, spiritual, and psychological health of an individual. According to Greisinger \& Jobánková (1990), disease is reflected in the individual through the following: 
- Rational attitude, which is affected by information and knowledge possessed by the individual in terms of the disease, as well as the knowledge, skills, and information on how the disease is perceived and how it portrays their future;

- Emotional-motivational aspect, which includes the emotional reactions caused by the disease in an individual. This includes emotions such as anxiety, fear, and optimism. The incentive is a change of values and interests.

- Behavioral area, which reflects attitudes to diseases that are rational and irrational, but also behavior in various situations.

Children respond differently to adults into terms of dealing with their disease. The child has less information than an adult about diseases or the severity of their condition on their lives. Unlike adults, children concentrate on current problems and mostly those affecting their emotions. For a child, the most important attitude and consequential behavior is that of their parents.

Any childhood illness represents a burden, not only on the body of the child, but also on their psyche. As defined by Vágnerová (1999, p. 73), "the majority of severe disease provides in the context of symptoms of disease a deterioration of the general condition, e.g. fatigue, exhaustion, pain". Children must adapt to new conditions, especially when in the hospital. They survive new and different occurrences than that experienced by their peers, and are unlikely to undergo any standard experiences.

The main influences on the psychological responses to an underlying disease, according to Vágnerová (1999), comprise the following:

- Developmental level and individual experiences, i.e., the already formed personality traits of the child; and

- The medium in which the child lives, especially its family, wider society, and the hospital staff.

A sick child is often under the influence of their illness and the consequences of certain isolation.

It is natural that all childhood experiences are reflected in a child's emotional survival, the intensity of which may not necessarily be directly proportional to the severity of the disease, but rather may associate with uncomfortable symptoms and subjective changes that occur around the child. The child may also be affected by previous experiences of disease.

A child survives their illness with increased irritability and emotional instability, they suffer anxiety and the uncertainty and fear of other annoyances.

Anxiety and fear can also transfer to the child from their parents, both verbally and non-verbally. Sick children are particularly empathetic to what is happening around them, especially in terms of their relationships with people to whom they are emotionally attached. Fear and anxiety are associated with a variety of physiological responses that can hamper recovery from disease and hinder adaptation to environmental changes during hospitalization. A sick child can be extremely sad, and feel hopeless and helpless (Harčaríková \& Nagyová, 2015).

\section{Incurable Illness in the Context of Family}

The family environment is particularly important at a time of crisis in the case of an oncological illness of a child or pupil. Vágnerová (1999) referred to this state of emergency in the context of the disease not only affecting the individual, but certainly the whole family on the basis of the disease being previously unaccounted for in the family's lifestyle and the change in relationships and value system of the family. Incurable disease is a burden that comprehensively amends the existing situation of the family (Nagyová, 2015b).

As stated by Vágnerová $(1999$, p. 58), "family represent to seriously ill individual the social group, which will enable acceptable social integration and provide the necessary emotional support". The family must become completely accustomed to the disease throughout its duration, as well as after the child's recovery from the illness. The family needs to comply with obligations resulting from the disease and the requirements of doctors. In the case of unfavorable development of the disease, such as when death of the individual results, the family faces tremendous sorrow and loss. 
Communication of a diagnosis of terminal illness of a child involves a strong emotional response for the parents. Vágnerová (1999) recognized the following emotional responses of parents towards an illness of a child:

- Fear and anxiety by way of disturbance of security of family environment on the basis of the disease, and treatment of a child in jeopardy;

- Anger stemming from concerns about the potential loss of a child; and

- Sadness and depression arising from a sense of helplessness and concern for the child.

The broader classification of Vágnerová (1999) for parental responses to the serious illness of a child compares with that of Kuzma (1999), which include the following:

- Confusion, where after the announcement of the diagnosis parents cannot understand details of the future treatment for their child. It is important that, after the initial shock, parents request doctors explain this information again;

- Rejection, where parents challenge the assumption of doctors and reject the possibility of their child having cancer;

- Concerns, where parents are afraid; they feel they are not strong enough to help their child; and they fear that this life situation is beyond their capabilities;

- Anger, where parents, through anger, express reluctance to concede without a fight (with the disease);

- Guilt, where many parents blame their child for causing the cancer; an incorrect and unjustified position;

- Mourning; and

- Fear about the social isolation, where parents are afraid of the reactions of their surroundings about their child's diagnosis.

Fear restricts parents' rational assessment of a child's condition. Their assessment is distorted by emotional burdens arising from the disease as well as from the lack of knowledge about the child's illness; the child's condition is evaluated on the basis of comprehending the surroundings, reading media, and their own ideas and assumptions (Vágnerová, 1999).

This attitude of parents may be misguided by their fears and concerns, understandably. Hence, medical teams need to provide parents with meaningful information that they can understand, as such information can change parental attitudes and stimulate active defense mechanisms that greatly affect existing perceptions of the disease as parents' endeavor to change the child's condition in a fight for their recovery.

In the process of activating defense mechanisms, parents divert initial feelings of helplessness and fear into an active effort to cure. At this stage, parents meaningfully help children being treated with positive attitudes and support.

Kuzma (1999) compiled a set of instructions for parents of children with oncological disease that have had a noteworthy and positive effect on children's recovery, and these are:

- At least one parent should be with a child in permanent contact to spend as much as possible time and communicate with parents of other children that are being treated;

- Parents should adapt their own behavior to the current state of the child; if the child is tired, do not distract them, but caress them, because physical contact is very important;

- Support the child with positive moments of contact with other children on the ward;

- Communicate openly with the child about his or her health and therapy;

- Provide the child support and confidence;

- Thoroughly prepare the child for medical procedures; and

- Take care not to disrupt normal contact between siblings.

Particular attention needs to be given to siblings of a child with oncological disease, because there is the likelihood that parents become focused entirely on the child with the disease. It is necessary that parents approach siblings openly and truthfully, providing them with medical information about the sick sibling. Parents should communicate open about changes in family functioning, and warn healthy siblings about possible physical changes of the sick child. 
Despite the provision of information and care to siblings of cancer patients, siblings often consider that they are neglected by their parents. Often they reflect on the changes and their responses are in the form of behavioral and psychosomatic survival and anger towards the parents. To avoid these negative reactions, it is necessary to provide psychological care for siblings of a child with oncological disease.

The author, Lamb (2001), reported these emotional reactions of siblings of a child with cancer:

- Fear of younger siblings is often an observed fear of contagion. They are not afraid that the disease affects them, but that the disease has affected their parents. Diagnosis changes the view of a healthy child in their world. With maturity, siblings start to fear the loss of a sibling;

- Jealousy, even when siblings fight for a sick child, the majority also appear jealousy. The sibling feels that all attention is given to the child with the disease. A healthy child is outside the situation, confused, and accuses the sick sibling;

- Guilt, many children in a fit of rage express false words, and where there is a situation that the sibling falls ill, they indict themselves for having spoken in such a manner. In this situation, children should be given clarification on the actual cause of the disease and that they did not cause the disease;

- Separation anxiety;

- Grief, healthy siblings can mourn for several reasons. One is fear of a sick sibling. Another is separation from a parent who is caring for the sick sibling; among the causes of sadness is separation from the sick sibling; and

- Anger.

Based on the above information, we performed research focused on various aspects of the life of individuals with oncological disease, and this contribution focuses on presenting the partial outcomes of a study focused on the problems of families of individuals with cancer. The research was carried out for three months from January 2015 until March 2015, when, through narrative testimony and structured interviews, we acquired research data from respondents who had been diagnosed with oncological diseases of specific soft tissue sarcoma, ependymoma, Hodgkin's lymphoma, or chronic myeloid leukemia (CML).

The aim of the research was to identify and describe the impact of the oncological disease on the family of individuals with oncological disease in the acute stage of the disease. On the basis of the research, we provide the following conclusions:

- Oncological diseases of individuals markedly affect the functioning of their family. The way in which the family will react and subsequently perceive illness of a child, affects the perception of the disease and access to treatment for the child.

- Relevant literature indicates that the family of an individual with cancer disease is affected by changes in the existing way of life. Based on our research, we emphasize that, while a change in behavior occurs on the part of the family, these changes are not significant and are only a temporary condition at the time of treatment.

- Parents of individuals with cancer are under enormous pressure and stress. Despite this situation, the parents of an individual with cancer will care and ensure the functioning of the whole family.

- The relevant literature indicates that siblings of individuals with cancer may be anxious, sad, or jealous. These characteristics were not present in the respondents surveyed. In contrast, relationships with siblings were described as positive and in-depth.

\section{Conclusion}

The expectation and birth of a child are one of the most important moments in life for a parent. A child presents for the parents a continuation and fulfillment of their wishes, since most parents expect that their child will be perfect. At present, when parents learn that their child is suffering from a serious or even incurable disease, it is an enormous shock, especially as their ideals and ideas for their child are demolished. The family at that time experiences psychological and social pressures. As pointed out by Vágnerová (2008), the social burden of this changes their social identity and thereby also changes behavior not only within the family but also within their wider social environment. 
The presented results of the investigation cannot be generalized to the entire population of students with cancer and their families with every student, as every diagnosis is specific in relation to age and social environment of the pupil, and the impact of disease on the family heterogeneous individuals. Our findings, however, point to the need for consideration of this issue, as oncological disease significantly affects the complex functioning of affected individuals in all areas of life.

\section{References}

Bild, R., \& Gómez, I. (2014). An Unwanted Journey. Creative Accompaniment in Pediatric Palliative Care. Bratislava: Plamienok Books.

Carstens, L. E. (2004). Teacher's Experience of Teaching in a Hospital School. Retrieved from https://ujdigispace.uj.ac.za/bitstream/handle/10210/711/LILLIAN.pdf?sequence=1

Crowley, L. (2014). Essentials of Human Disease. Retrieved from http://www.jblearning.com/samples/0763742317/Crowley_Human\%20Disease_7e_Ch01.pdf

Greisinger, J., \& Jobánková, M. (1990). Introduction to psychology for paramedical staff. Martin: Osveta.

Harčaríková, T. (2011). Pedagogy of physical disabled, ill and health debilitated- theoretical foundation. Bratislava: IRIS.

Harčaríková, T., \& Nagyová, K. (2015). Education of individuals with incurable illness as a multidimensional problem. In MULTIDIMENSIONALITY basis of the current development of special education. Bratislava: PdF, s. 183. 2015

Jasenková, M. (2005). How to live together until the end ... Children's home hospice care. Bratislava: Plamienok.

Jasenková, M., \& Mikesková, M. (2005). Helping live and dying, rejoice and grieve. My child patient is terminally ill, what's next? Bratislava: Plamienok.

Kapr, J., \& Muller, Č. (1986). Book about illness. Praha: Avicentrum, health publisher.

Kuzma, I. (1999). Malignant tumors in childhood. Advice for parents of children and adolescents suffering from malignant tumors. Bratislava: League Against Cancer SR.

Lamb, L. (2001). Siblings of Children with Cancer. Retrieved from http://www.oreilly.com/onconurse/welcome.html Nagyová, K. (2015a). An individual with incurable disease in the context of education: dissertation project. Bratislava: PdF. Nagyová, K. (2015b). An individual with oncology disease in the context of education: diploma thesis. Bratislava: PdF.

Nagyová, K. (2016). The importance of pedagogy of ill in the education process of individuals with oncology disease. Trnava: JUVENILIA PAEDAGOGICA 2016.

Svatová, M. (2010). Chronic disease and its social consequences. Retrieved from http://www.pulib.sk/elpub2/FF/Balogova1/pdf_doc/38.pdf

Vágnerová, M. (1999). Psychopathology for helping professions. Praha: Portál.

Vágnerová, M. (2008). Psychopathology for helping professions. Praha: Portál. 